\title{
Effects of human-machine integration on the construction of identity
}

\author{
Francesc Ballesté (Humanitats, UOC, Barcelona)
}

Carme Torras (Institut de Robòtica i Informàtica Industrial, CSIC-UPC, Barcelona)

\begin{abstract}
Recent developments in social robotics, intelligent prosthetics, brain-computer interfaces and implants pose new questions as to the effects of technology on identity, society and the future of humankind. Our standpoint is that such effects cannot be studied separately from their social/cultural context, and thus we begin by reviewing the existing approaches to the social construction of reality, placing special emphasis on language and its limitations to describe the future. Then, we focus on the body as the place where the human-machine integration occurs, and we describe four levels at which the notion of cyborg has been analyzed in anthropological studies: symbolic, physical, as a permeable layer between nature and culture, and as an intermediate step towards a higher-order existence. We end up with a word of caution in relation to technological determinism stemming from STS (Science and Technology Studies), as well as the need to establish Relevant Social Groups (RSG) with well-founded criteria that join scientific and sociological academics under a multidisciplinary approach.
\end{abstract}

\section{Introduction}


Our aim is to study the basic factors to be considered when exploring the effects of technology on identity and its impact on society. We see that there are three such factors.

First, we follow the thesis of Ihde (2004) regarding technological 'multi-stability' in that predicting the effects of a new technology is difficult because of the appearance of unforeseen uses for it. In fact, this stands as the main problem that Humanities face in this domain. Looking around we find many examples. One of the most recent is the riots occurred in the surroundings of London. The Guardian (2009) reported that mobile phone companies would help in the search for individuals who used the messaging system included in Blackberry devices to promote violence. Note that, at first, this platform was designed for business communication. For this purpose, one of its advantages is the use of an encryption system that prevents the open reading of messages, which is precisely what favoured the criminal activity.

Secondly we must highlight the importance of the social/cultural context in which people's identity is developed. The complex uses of some devices cannot depend only on how familiar we are with their specific field of application, but also on the knowledge inherent to socialization processes that allow the individual to adapt to new circumstances and expectations. However, this knowledge is applied according to the perceived needs. We will analyze the importance of habits, the objectification of shared knowledge and the construction of roles. Such issues become more complex as the devices tend to increase the interaction with people to become extensions of their bodies or insertions into them. 
At this point, to place in context the analysis of individual actions and behaviors such as those in the Joe Wooller (2010) case - we will mention the major perspectives from behavioral psychology, cognitive (Piaget, Vigotsky) and cultural psychology, recognizing there are points of disagreement between some of these. To this end, we will highlight Turkle’s (2007) perspective on the use some communication technologies. However, since individuals are social beings and technological devices emerge and influence in this context, it is justified to approach the construction of identity on the referential basis of Berger and Luckmann (1966) and their theory of "construction of everyday reality”.

Third, we must pay attention to the importance and potential significance that some sectors give to the current technological innovations and those hypothetically future ones (transhumanist theory) in relation to the ideal model of society that we define nowadays as State of Welfare. Current priorities are based on the efficient management of public resources in harmony with the interests of parallel organizations and other institutions that make up a heterogeneous network of power relations. The evolutions of collective needs are diverse in nature, energy, optimization of time, and affect the concepts of life and death in the fields of prevention and palliation of illness, rehabilitation and reintegration of individuals. All these are set in a framework of complex relationships that contradict the widespread - and seemingly powerless - idea that technology evolves sequentially, independent of other factors. Thus, we will try to make a brief but clear distinction between some aspects of 'technique' and the use made of the 'technology' itself. Some of the traditional tenets of the philosophers of technology (Habermas, Heidegger, Ellul) have been branded as pessimistic, but at a 
fundamental level we still consider them appropriate. This is so because of their content as well as the epistemological challenges they pose today to Science and Technology Studies (STS) as regards to the definition of cyborg - that we will approach from the Anthropology of the body - as the paradigm of symbolic man-machine integration. In this direction, we will analyze the challenges posed by the work of Kevin Warwick (2011), its relationship with the limitations of language and the introduction to the fundamental idea of Cyborg Anthropology.

\section{Preliminary concepts on the social construction of reality}

Our study aims to analyze the influence of language as a mechanism of objectification of collective knowledge in a technocratic society and its symbolic universe. From our point of view, this is important in two aspects:

The first is to study the main features of everyday reality that are based on the "taken for granted". The adhesion of the individuals to a cultural system previous to their existence endows them, at the same time that it limits them, with the discursive possibilities that allow them to explain their own acts, which are also limited ${ }^{\mathrm{i}}$ (Habermas, 2001). Especially those related to technology and the ability to build or bring out different identities in a single individual.

The second aspect refers to the characteristics of language that make it an effective tool as a mechanism of adaptation to the "here and now." But although language also gives individuals the ability to project themselves mentally into the future, it is certainly 
ambiguous and ineffective to predict future events reliably. We will analyze this inherent limitation.

To begin with the first aspect, the vast majority of actions we take during the day are not the product of conscious decisions. On the contrary, mundane everyday actions resolve most situations we can find, because the cost in energy and time to make conscious decisions would be excessive to waste them on routine and repetitive actions. However, our perception of our actions is in the 'here and now'. That is, it is characterized by a sense of immediacy. Thus, our perception of time is one of the key ingredients of the mental construct we experience when we interact with people or objects - in addition to the information specific to the object itself - and that end up being determinant. We realized this, for example, in the first video conferencing equipment, where image and sound rarely came up in synchrony. In fact, adaptation to human response time is one of the current challenges of technological innovation.

In summary, the relationships we can establish between people and between them and objects are characterized by bidirectionality and reciprocity in the intervention of the senses - including the body (Goffman, 1959; Martí, 2008) - through a specific perception of time to which all of our goals adjust. The transformation of the body is one of the ways of communication that humans can establish with other humans and objects in a bidirectional way. The body is thus, simultaneously and at all times, the consequence and origin of action. However, our actions affect identity to the extent that we modify our behavior according to the context and pre-established role, previous to individual existence. Indeed, the processes of knowledge construction objectified through language lead to the institutionalization of roles (Berger and Luckmann, 
1966). At this point we must understand the roles as the consolidation of habits with significant social relevance, derived from the specialization of human activities ${ }^{\text {ii }}$ in hypercomplex societies (Morin, 1995). Rogers (1962) remarks that most decisions related to technology occur long before its process of diffusion starts. Indeed, this order of objectification occurs as we share the system of linguistic signs ${ }^{\text {iii }}$ that helps build a 'social knowledge repertoire and typifies it' (Berger; Luckmann, 1966).

The importance of language in the 'here and now' of individuals is highlighted by two basic functions: First, insofar as one builds his own discourse towards something, experience, etc.., he comes in contact with his being and this becomes evident in the discursive possibilities available. On the other hand, as one shares his knowledge and others adhere to it, he undergoes a gradual process of depersonalization that is accentuated with the passage of time, conferring a historicity that legitimizes the symbolic categories on which that knowledge is constructed (Berger and Luckmann, 1966) (Cole, 1995). That is, a regulatory framework is built that serves as a reference for all human activities (Edwards and Potters, 1992). Thus we see that humans are producing their social world and, in turn, with the passage of time they also become its product. We can say therefore that the identity's site is the symbolic universe that governs our daily life within society. Here is where identity is constructed and transformed in a continuous reciprocity context (Vayreda et al., 2009). However, this continuous reciprocity is also the foundation of the learning processes in relation to machinery and it contributes to building a knowledge that is characterized by the psychological internalization (integration) of its use $\mathrm{u}^{\mathrm{iv}}$. One consequence of this is the construction of discourse made by individuals at the time to explain their own actions so 
that - depending on the uses and types of technological devices - may allow an objectification of social response of acceptance or reject.

Social networks on the Internet open up the possibility that one individual can construct multiple coexisting identities. The versatility of these networks lies in the fact that they can simulate situations in which individuals can be identified differently depending on contexts and goals. However, this identification-identity is consolidated to the extent that it is backed up by other individuals using the network (Vayredaet al., 2009) ${ }^{\mathrm{v}}$. Thus, in the Internet, at the same time that a role is exercised in a particular context - by versatility of virtualization - all other possible roles are hidden.

This approach follows the thesis of the SIDE model (Social Identity model for Desindividuation Effects) affirming the possibility of studying the Internet as a social space with limits and rules as are found in everyday life vi (Spears et al., 2002). We adhere to the same approach but taking the perspective that prioritizes the use of language to the extent that, beyond the mere human-machine interaction, it makes the psychological integration of the uses of technology possible. The model of Social Discursive Psychology is based on the analysis of discourse and the dissolution of the dichotomy between inner and outer (individual / society) mentioned by Potter and Wetherell vii (Garay et al., 2005).

An example of practical application of the approach we advocate for is the case of Joe Wooller (2010) ${ }^{\text {viii. }}$. He is a young man who, tired of always carrying pockets full of keys, decided to set up a subcutaneous chip in his right hand by means of which, through radiofrequency, he could open the door and start the car, the two especially 
adapted to receive the signal. We consider it a special case study because he uses the human-technology integration to continue doing something common, but in a unique way, unusual compared to any other individual. The fact that even today there is no habit socially relevant "here and now" of implanting a chip makes it particularly interesting to study the understanding he has of this action and, therefore, of himself. If his use of the technological device is mediated by historical relationships that characterize the daily reality of his culture (Vayreda et al., 2009), then it makes sense to ask for the forms of relationship that he builds through the discourse on which his action depends (Vayreda; Vila. 2009) ${ }^{\text {ix }}$. That is, it would resolve the question: What kind of discourse on himself can an individual build when he performs an action that doesn't have any social significance? Given the above, to what extent the use of the device may be appropriate or inappropriate with respect to its possible expansion and social impact?

A second example of applicability of the proposed approach, and at a much greater level of technology integration, is the research of Kevin Warwick (2011) on the implant of a chip connected to the nervous system. In these tests, alternative technological solutions to traditional medicines for preventive treatment of episodes of depression and Parkinson are being considered. Obviously, reasonable doubts about their long-term effects on the rest of the organism, including brain capacities, have arisen. We must ask ourselves to what extent the activation of programmed electrical impulse in a chip inside the brain has in mind, or not necessary, possible external factors that contribute to a depressive emotional state. Risk factors that may have to do with the processes of socialization, habituation, etc. That is, to what extent, an electrical impulse interferes the dynamic, reciprocal and discursive building of identity? Undoubtedly, the field of 
collaborative work between the world of the humanities and technological innovation is as broad as exciting ${ }^{\mathrm{x}}$.

This leads us to address the second issue proposed above concerning the limitations of language to try to describe the future. At this point, we realize that, beyond the immediate present, language - although we allow individuals to project themselves mentally into the future and have expectations - appears necessarily generic. Future realities we may think of today are still lacking a historicity on which a discourse that transcends linguistic categories and dichotomies of our present symbolic universe has been constructed (Haraway, 1991). Thus, based on the above, we propose thinking about the imprecision, ambiguity and perdurability in time of the use of some linguistic terms that use nowadays to try to describe a hypothetical future.

If in the future - as proposed by Kevin Warwick - by combining remote and neuronal connections, emotions could be transmitted between distant people without the intervention of intersubjective language (Evers, 2009), then the - necessarily ambiguous - distinction between persons 'implanted' and 'not implanted' could be socially transcended. It would eliminate the need to share the emotions textually, but not that of constructing a discourse about ourselves. This poses the following question: Would a stage be reached where individuals, as both products and producers of the textual reality that surrounds them, could do without the language objectifications supposedly transcended by Warwick’s Cyborg and just use language subjectively? The question is entirely appropriate given the existence of theories (Sapir-Whorf) that, though accepting the existence of relations between language and thought, do not give them an exclusive determinism in the construction of knowledge. The basic question 
underlying these issues is whether the use of some of the categories (implanted vs. non-implanted) reveals the advent of a new symbolic universe - supposedly transhumanism $^{\mathrm{xi}}$-, parallel to the daily one, or just the ongoing natural mutation of the already existing to the majority.

All this brings us to reflect on the mechanisms of knowledge construction in humanmachine integration, taking as departing point the works of Jean Piaget (more focused on the interaction with objects), and those more recent of Turkle (2007) with infants between 5 and 13 years old. Regarding the transformation of symbolic universes, through human-machine integration, one of the significant findings is that improving the interfaces may depend on our understanding of how our own emotions, vulnerabilities, feelings, etc. are built. In her study, it is very interesting to note the possibility that children of certain age - unlike adults - do not need to build any notion of human being based on the material that people or machines are made of.

\section{The body as the integration place: towards the cyborg.}

Our approach aims to place in context the concept of Cyborg, viewing it from different perspectives compatible with one another. First, we study the relationship between body modifications from the standpoint of the Anthropology of the body, i.e., as a cultural expression of humans, regardless of the means used. Thus we start with an overview on the current meaning of cyborg, which will lead us to reflect on what it 
means to be hybrid and where it comes from. Secondly, we enter into the question of the effects of technology integrated into the body and the possibility to reinterpret its meaning as a continuum that breaks the historical dichotomy between Nature and Culture: rather as something permeable. We will also review how the traditional approach - one that distinguishes Technique versus Technology - has influenced other more modern approaches, leading to the third and final point of this article.

Several authors have reflected on the concept of cyborg and have tried various classifications. Some historians and philosophers have made a very careful analysis of the consequences of technology on the nature of human existence described by Habermas (2001), Ellul (1954), Jonas (1979), etc., and also the thesis of Clynes\&Kline (1960), Haraway (1991), Foucault (1975) and Gray (2002), among others, regarding the study of the hybrid nature of the cyborg. Therefore, it is clear that when we intend to discuss the cyborg, we want to go beyond the classic idea of Cybernetic Organism. What can be inferred from studies such as those of Aguilar (2008) or Campàs (2005) of the above-mentioned authors is that the cyborg can be approached from four related perspectives.

In the first place, the cyborg emerges as the material product of an interpretation of the codified body, transformed into textual information. This possibility of textualizing the body permits, in the second place, the physical integration between machine and human being. The different integration levels would allow us to distinguish certain types, from the communication interfaces to military exo-skeletons and medical prostheses (Aguilar, 2008; Gray, 2002). Now, thirdly, the cyborg interpretation of Haraway (1985) focuses on the reconsideration of the boundaries, which are questioned 
and fused. Not only in order to permit building new ones, but because the malleability of integration between technological objects and humans may lead to transcend opposing pairs embedded in our symbolic order, between the physical / non-physical, human / machine, etc. (Campàs, 2005). The fourth aspect of the cyborg establishes manmachine integration as an intermediate step (postmodern dichotomy) to a higher-order existence in which the body would be unnecessary and a new symbolic order would arise (transhumanism).

We believe that, before entering into other issues, a brief contextualization from an anthropological perspective of the body modifications that today can be attributed to the cyborg is required. Numerous cultural evidences reveal the need to transcend the limitations of the body at birth (Berger and Luckmann, 1966) and to attribute a symbolic meaning to it by means of modifications or intervention ahead of time. Death is one of these limitations. There are places where one has been able to incorporate it socially and symbolically transcend it. For example, there are cultures, such as that in Hainan Island (China), where the bodies - of women, in this case - are tattooed after death to be recognized by their ancestors at the time they meet (Martí, 2008). Some of the most well-known cases are the skull deformation of the pre-Colombine period, the bandaged feet of Chinese women, to make them the smaller possible as a symbol of social status, or the neck lengthening of giraffe women by some ethnic Burmese groups.

Following Le Breton (1994) and Douglas (1970), it appears that everything affecting the body and how it is shown affects social ties symbolically, whatever the culture we talk about. For example, in the western world, the technologies of assistance to procreation permit, in some cases, that the mother of a barren woman lends her uterus to 
be artificially inseminated (Le Breton, 1994). However, in ethnographic literature it is a classic case that of the Nuer tribe in Africa, widely studied by Evans-Pritchard (1940), where the barren woman is viewed exactly as a man and she can have several women if she can pay them. These women may be fertilized by relatives or friends and their children will consider the barren woman exactly as any other father.

A conclusion to be drawn from these examples is the importance of anthropological observation and fieldwork, taking the ethnographic literature as reference and opening up the possibility of extending it to other areas such as the cyborg. In this respect, the work of Lucy Suchman and Daniela Cerqui is especially relevant. The examples are particularly interesting because they highlight the satisfaction of some needs that may be common to different cultures, questioning the technological determinism and autonomy of some innovations.

From this point of view, Le Breton wonders what remains of the body when its symbolic, social dimension is withdrawn. For example, telepresence technology raises the hypothesis that future inter-subjective relationships may become completely virtual, a projection of the collective imagination. The effectiveness of telepresence in the world of everyday life and social relationships, even sexual ones, could be so important that people would probably spend most of their time connected to the interface without leaving home. This would lead to the paradox that, trying to give people a completely independent life, would end up unplugging them from society to plug them back to a machine. 
Lombard and Ditton (1997) perfectly relate the technological factors that mediate the perception of presence (image quality, image size, dimensionality, camera technique, interactivity, etc.) to the psychological and social mechanisms triggered in individuals who use from TV to virtual reality. Their review is especially interesting in three aspects directly related to our work: 1 / The study of interactivity yielding an analysis of the requirements and variables needed for its efficacy. 2 / The statement that six descriptions of telepresence share the illusory perception that there is no interface mediating what we perceive through technology. 3 / The similarity of the psychological processes and emotional responses of human-human interactions and human-machine ones, even when there is awareness of technological mediation.

Still, however, the symbolic dimension of our universe is constituted today by the mutation and eventual death of the body. Stripping it would endanger the foundations of our construction of everyday reality as we know it. (Le Breton, 1994; Berger and Luckmann, 1966).

According to the development made in the previous point, as regards to the symbolic dimension of the body exposed above and the current prospects of technological development, two aspects must considered. From the standpoint of the outside social world, a device used to prevent discrimination of an individual because of his disability is unlikely to trigger rejection, because, in relation to other people around, it will help him to continue doing the same things he did before. From the point of view of the inner world, being deprived of one member entails the impossibility of building one's own body, of giving a meaning to it. In short, it prevents to pursue the discourse about the self in relation to the capabilities of interaction, of receiving information and 
building the knowledge previously allowed by that part integrated in the whole body. Moreover, there are devices that suppose, apparently, a qualitative improvement of human capacities. The case of the athlete Oscar Pistorius (2011) is certainly significant. Despite suffering a double leg amputation and having to use prostheses, he has been able to compete in the recent world championship in Daegu (South Korea) with the other non-disabled competitors due to a resolution of the Court of Arbitration for Sport. At first, his request to the IAAF was denied. And this decision could be considered a good reflection of what often happens in the outside world. That is, the fear of the consequences caused by difference when this may imply loss of power by others can lead to discrimination ${ }^{\text {xii }}$.

Focusing now on the effects on the body, we have the example of traditional prosthetic extensions that will incorporate software to obtain additional data in real time. Note that traditional glasses have always functioned as prostheses capable of correcting beforehand the information that will go across the vision system and eventually reach the brain. Depending on the degree and type of vision of the individual, technology to build interfaces may vary. Thus, as regards the concept of 'Augmented Reality', we refer to the exposition of the Theoretical Physicist Michio Kaku (2010) at the Bdigital Global Congress (2011) in Barcelona in its twelfth edition. According to his view, in the near future glasses or contact lenses may incorporate a microchip including sensors capable of recognizing the objects or people we observe and - in response to the number of blinkings - show us additional information about them. Actually, the distance between what we have just explained and the capacity of mobile phones to recognize three-dimensional codes and display their associated information is very short. 
In another edition of the same conference, Robert Leeb (2009) presented the progress of his research program on noninvasive brain interfaces (BCI) combined with the use of Virtual Reality (VR). The aim is to facilitate the movement of a person in a wheelchair by playing and transmitting signals from the brain to the electrical servo chair when interacting in a virtual setting for experimentation. However, recent investigations of Professor Kevin Warwick have lead to successful experiments with mouse neural cells cultivated in the laboratory, which, once embedded in a matrix of electrodes, are capable of generating responses to external impulses and control the motion of a small robot ${ }^{\mathrm{xiii}}$.

The point of agreement between Kaku and Warwick on the future of human society lies in its complete integration both in the Internet and in the use of chips everywhere, including the own body. In short - and under the sociological and anthropological approach - all this shows the importance of the body, not understood as the traditional boundary between the exterior and the interior, but as a layer characterized precisely by a permeability that channels material production (world of experimentation: Body One) and symbolic production (social world: Body Two) (Ihde, 2004). Thus, the integration of technological devices would only accentuate a natural human condition, which is part of the context that also builds the intersubjectivity of identities (Vayreda et al., 2009). Therefore, we find that the overcoming of the Cartesian mechanicism leads to the current post-modern deconstruction of the body, offering the chance to transcend its limitations (Aguilar, 2008). Obtaining knowledge about the biological and physiological functioning, needed to integrate the devices in the body, may lead not just to cure it but to improve it. Thus, we think that the Cyborg goes beyond the body seen as a completely permeable layer, diluting it by 
changing the subjective self-understanding 'about us'. We stop distinguishing between "being body" - in which individuals are born naturally - and " having a body" which can be modified through technology - (Habermas, 2001) to become a "work in progress" (Campàs, 2005) on a biological information susceptible of being controlled (Levi-Strauss, 1955). Although we would agree with Aguilar (2008) to not share the pessimistic view of Levi-Strauss with regard to the control of information for enslaving purposes, the relationship with the functioning of economic and political systems should be noted (Aibar, 1999; Rogers, 1962). The clearest example today is the field of biotechnology.

Indeed, the objectification of knowledge that the cyborg entails - in merging identity (habit, explainability, historicity) and object (chips, prosthetic devices) raises the question of up to what extent it also dissolves the boundary between Nature and Culture. The way humans relate to their own nature (and possibly improve it) is itself the expression of technological culture (Vayreda et al., 2009; Aguilar, 2008). The dilution of these limits, the freeing of the dichotomies through the cyborg (Haraway, 1991), highlights the historical and hybrid nature of humans toward technology (Law, 1991). Hence, would a classification differentiating “implanted” and “no-implanted” continue having some meaning? If the successful integration of physical devices depends rather on a psychosocial internalization, perhaps it makes more sense to view the cyborg as a continuous whole in all that pertains to the study of man (Downey et al., 1995).

However, this view of the technocratic endeavor led to the epistemological distinction of Technology by numerous thinkers such as Heidegger (1984), Ellul (1954), 
Jonas (1979), Habermas (2001), and Ortega y Gasset (1939), as well as those who later revised this approach such as Latour (1999), Foucault (1975), Law (1991) and Sloterdijk (1999). Reference to these authors is, therefore, unavoidable. This first approach essentially contributed to reconsider the understanding of social processes and their influence - as techniques ${ }^{\text {xiv }}$ - on the not foreseen or not desirable uses of technology. Thus viewed, it is paradoxical that the technical condition of human nature gives rise to the possibility to dehumanize (Habermas, 2001). Within this context, we must cite the work of Jonas (1979) and his "principle of responsibility", as well as Heidegger's moral conception of a modernity in crisis (Rodriguez, 2006).

Today, however, the possibility of a hybrid human - the cyborg described above suggests the idea of a "socialization of the non-human" understood as the process by which a device modifies human agency as regards to the efficiency of technical action (Latour, 1999) ${ }^{\mathrm{xv}}$. Hence, we resort to the words of Heidegger (1984): 'it is through technique that we perceive the sea as navigable', in that they convey the idea that the effects of the devices are never neutral. The efficiency of the technique due to the socialization of the non-human (devices) widens reality with new possibilities while at the same time raising different problems. This approach, contrarily to the one above, avoids the epistemological error of technological determinism and autonomy, and helps raise the question of the cyborg in other terms. The mentioned examples and the conclusions that can be drawn from the work of Turkle (2007) ${ }^{\text {xvi }}$ open up the possibility to consider the possible mutation of the concept 'humanity' rather than make us think in terms of 'dehumanization'. This appreciation is also consistent with the semiotic perspective of Ihde (2004) and the leveling of the dichotomies raised by Haraway (1991). Along this line, it is also interesting to wonder what the human 
attributions will be when the first humanoid robots, such as those by Hiroshi Ishiguro (2011), reach Japanese homes; although this is more a matter of interaction rather than integration.

Clearly, however, current epistemological approaches are not exempt from problems and disputes. Admittedly, the Sociology of Scientific Knowledge can predict only a very small part of techno-scientific activity (Aibar, 1996) ${ }^{\text {xvii }}$. Today, however, the model known as Actor Network Theory (ANT) (Callon, Law, Latour) seems one of the most appropriate ${ }^{\text {xviii }}$ when trying to explain the product of man-machine hybridation. Interestingly, this perspective aims to study the "black box" involved in situations of symbiosis between social processes and the dynamics of technological change (Aibar, 2006) before it closes and gives rise to the cyborg, with a different attribution of agency from the one that human and machine would have separately (Latour, 2001; Ihde, $2004)^{\mathrm{xix}}$. Ihde openly defends the intervention of humanists within R\&D laboratories. One aim would be technological evaluation within the studies defined with the acronym EPISTLE $^{\mathrm{xx}}$.

Given the experiences recorded and the methodological perspectives developed, recognizing the possibility of a natural hybridization between humans and objects/devices gives rise to the approach of Cyborg Anthropology (Downey et al., 1995). This aspect of anthropological study suggests a different formulation of the history and subjectivities that includes interaction/integration of humans and machines, not as a simple expression of cultures, but bearing in mind a possible reformulation of the traditional concept of Anthropos. 


\section{Theoretical background and discussion of Technological Determinism.}

Our goal is to explain and succinctly place in context technological determinism, as well as to describe the way it is approached within the field of STS.

Any sequential chronological reconstruction of the appearance of technological devices - which results in an exponential graph - try to justify what has been called deterministic technological evolution. This view has been reinforced by the everyday perception that technology evolves at its own pace, invulnerable to external influences. Its credibility relies on the idea that the current unprecedented technological revolution will be able to determine future social changes. Moore's Law is often used to sustain this claim. Aibar (2006) suggests that there may be more suitable alternatives, based on the historical knowledge we possess today, to reconstruct all the factors that influenced the realization of the devices.

First formulated in 1965, Moore's Law (which is not a law in the literal sense of the word) states that the number of transistors that can be placed inexpensively on an integrated circuit doubles approximately every twelve months, while keeping the manufacturing cost. In 1975, this prediction was revised and the time period extended. Certainly, as we explained earlier in this article, today by our own experience as consumers of computers - and in the world of technology research no one seems to doubt it - this growth has an exponential character.

Some authors recognize that Moore's predictions of technological evolution should not be limited by taking only as reference the field of integrated circuits (Kurzweil, 
1999). The analysis of Kurzweil is based on the analysis of forty nine devices grouped in five categories by taking into account the criterion of technological complexity, from lower to higher: 1 / mechanical computers, 2 / electromechanical computers (made up of relays), 3 / computers of vacuum tubes (valves), 4 / transistor-based computers, and 5 / computers made of integrated chips. He defends the idea that the exponential growth of technology is prior to Moore's statement and that the law refers only to the fifth developmental category. The location of the devices of the different categories on a chart plotting age of onset (x axis) and number of calculations per second (y-axis) looks exponential (Kurzweil, 2011).

A theoretical consequence of this evolutionary view of technology provides the foundation of the transhumanist perspective (Kurzweil, 2011-b) and the hypothetical generation of a new symbolic universe, as explained above. Inherently, it leads to a revision of the idea of human society and identity, including the question of faith (Stock, 2011; WTA, 2011).

The starting points and assumptions of technological determinism are not without controversy, of course. The scope and influence of its effects on contemporary society historically attributed to it are studied within the field of Anthropology and Social Sciences. Disciplines that are relatively young, since they started with the early to midnineteenth century theorists (Marx, Comte, Darwin) and founders of Social Sciences (Weber, Durkheim, etc.), but which have enough historical background to have surmounted some methodological biases, evolutionary in nature, especially in the field of Cultural Anthropology and Religion, as well as the ethnographic work since the early twentieth century and the interwar period (Benedict, Levi-Strauss, Pritchard, White, 
etc.) (Llobera, 1999). With this, we like to say basically two things: 1 / Despite the historical journey of these disciplines has not been devoid of internal disputes, there is some agreement that what defines a culture and determines its future is not just the evolutionary stage of one of its many possible indicators: technology, in this case. This often led to ethnocentric positions that have impeded rather than facilitated the study. 2 / One of the challenges of Social Sciences, Anthropology and Philosophy of Science of the last thirty or forty years until now has been to find the interdisciplinary approach appropriate for a Sociology of Scientific Knowledge.

Until this interdisciplinary approach has begun to take shape, scientific activity has been considered isolated from other social processes which, in fact, have shaped it. Their performance and results have transmitted the image of a scientific autonomy impervious to the social sciences until the arrival of authors such as Quine, Kuhn and Feyereband. Sociologists of the University of Edimburg highlighted the imbalance between the generation of scientific knowledge and the lack of social context of their own scientific activity. Part of the result was the adoption of the ethnographic method of anthropology within laboratory: participant observation. In the mid eighties, the Fort Program had the aim of explaining the factors and dynamics that produce technological changes. That is, for the first time it was challenged that the engines were the result of successive improvements and optimizations (Aibar, 2006).

Applying what has been mentioned so far as regards to the idea of technological determinism, we must recognize two things. The first is that the activity of Science and Technology Studies is still so new that it is virtually impossible to find this in many of the institutional sectors dedicated to technological innovation and manufacturing. 
Studies of technology evaluation (EPISTLE) are not common. There are humanist perspectives (Ihde, 2004) that propose to study the possible negative effects of technologies in order to gain a deeper knowledge before they transcend to society. In this direction, the first institutional attempts go back to the seventies with the establishment of the Office of Technology Assessment in 1972. A cause of its failure were the strictly scientific reports that were maintained separate from the socio-cultural sphere and public opinion (Aibar and Díaz, 1994) ${ }^{\mathrm{xxi}}$. These authors, however, are quite skeptical about the possibility of predicting the future based on the quantity and reliability of the information gathered. Moreover, the few attempts that have been made in Technology Assessment have been based, paradoxically, on the implementation of more technological devices that tried to make the task easier. Aibar and Díaz’s proposal relies on the fundamental idea that no single methodological model may apply ${ }^{\mathrm{xxii}}$. But these viewpoints still lack institutional inertia, and to some extent disregard the academic tradition of ethical concerns due to Habermas, Jonas, Adorno, Heidegger, Ellul, Ortega y Gasset and Hottois.

The second is that, despite the above, the concept of technological determinism proposes a one-way relationship between technology and society, highlighting the technological factor as the sole engine of the other factors of social change. Which, today, with the recent virtues and drawbacks of STS - and its sociological inheritance we know it is not like this. In fact, Rogers (1962) confirms this point by opposing to the concept of traditional technological development based on phases in a lineal temporary structure (1: Needs/problems, 2: Basic research, 3: Development, 4: Commercialization, 5: Diffusion and Adoption and 6: Consequences). In the last few years, there have been many proposers of different perspectives to the study of the interactions between 
technology, science and society. From the study of scientific controversies (Pickering, Pinch, Collins), the Ethnography laboratory (Latour), scientific ethnomethodology (Lynch, Garfinkel) through the Actor Network Theory (ANT) (Latour, Callon, Law), which we thought to be the most appropriate in the previous section.

From this perspective, theories of a hypothetical future based essentially on technology lack not only an objective view that considers the heterogeneous nature of all the involved factors already shaping the present, but also a methodological perspective that recognizes the difficulties of accurately analyzing them. The latter represents a field of study itself.

For example, throughout our study of fully man-machine integration - called Cyborg or radical extension, as proposed by transhumanism - we have encountered several difficulties that could be grouped in two categories according to the STS tradition:

1 / Exogenous: technological products constantly feedback and influence social interactions that are today hyper-complex themselves. The relevance of human actions economic, political, etc. - is influenced and in turn influences the socialization of the devices (Rogers, 1962). Both are transformed continuously through this mutual interaction. We know that the derived factors of social change to be studied do not depend only on the effects of devices that have come to materialize. 
2 / Endogenous: One of the key questions is to carefully study the ' required waypoints ' or 'interpretative flexibility' that determine the realization of a device before it occurs.

Whatever the perspective adopted, it will have the capability to influence the collective projection of our future as a society, because of its relation to 'how we will explain ourselves' at the time. The concept of technological determinism comes into direct conflict - among other factors to be discussed below - with the assumption of heterogeneity transmitted by any of the perspectives taken by STS, due to the dichotomy (technology vs. society) inherent in the unidirectionality of its proposal (Rogers, 1962). Indeed, the frontier between technology and society is certainly blurred, as shown by classic case studies such as the revision of the social impact of the stirrup (of Chinese origin), the one conducted by Callon on the impulse of the electric car (VEL) in France, that about the QWERTY keyboard ${ }^{x x i i i}$, or the study of Pinch and Bijker on the modern bicycle. The basic problem that these examples show is that, whereas it is easy to take into account expectations about future social changes that are essential for the devices to materialize, these can be frustrated due to their being inconsistent or unrealistic, or rather due to the unexpected interpretation of future collective needs which are juxtaposed to those perceived within the innovative action itself. Furthermore, Rogers (1962) points out the difficulty to generalize, from case studies, the long-term consequences of the process of technology diffusion. This adds to the multi-stability factor noted by Ihde (2004) in that the adoption of some innovations is not always positive and predictable.

The more consistent and stable is the network of heterogeneous relations built, the more likely it is that the device materializes (Vayreda et al., 2006; Rogers, 1962). Many 
variables make this equilibrium very fragile along the temporal process of technological innovation. Rather than the nonexistence of such dichotomy, the fundamental issue is that the two terms are the same (Seguí, 2005).

Another problem of technological determinism discussed in literature is the tendency to reconstruct the history of artifacts taking the current ones as models, as if they were the best possible solutions carried out in time, thus giving rise to extrapolations about the future. Studies conducted by Thomas P. Hughes (1987), taken as reference precisely in the supercomputing field, discredit any historical reconstruction of devices based solely on efficiency criteria and not properly contextualized.

The discussion above points towards the need to expand the scope of the debate on the influence of technology in a technocratic society by opening it to public opinion, providing mechanisms for the establishment of relevant social groups (RSG) with wellfounded criteria, such that scientific and sociological academics are encouraged to work together under a multidisciplinary approach.

\section{Conclusions.}

Identity is an attribute of what we consider human and which is susceptible of integration with non-human technological artifacts. Thus, it was essential to begin by studying the factors involved in the construction of identity, including the body. Second, it has been important to approach the deterministic view that science and society have taken on technological innovation. 
The objectification of knowledge about human activities through language permits a dialogue between individuals and society. The Sociology and Ethnomethodology of Discourse makes it clear that the construction of identity and the learning of socially-relevant habits are inseparable. Obviously, all the habits related to the use of technological devices should be included, because they develop essentially within a psychosocial integration process. Thus, any technological modification of the body leading to the cyborg affects daily actions and the learning of habits in its symbolic dimension. This includes the ability to transform the symbolic universe that underlies the construction of identity. On the other hand, the analysis of some examples of technology integration from the perspective of Cognitive Psychology has led us to overcome the Cartesian dichotomy between external and internal, revealing the body as a completely permeable layer, as a work in progress.

The effects of this permeability - symbiosis between human and nonhuman - lead us to think about a symbolic mutation of the concept of human being, i.e. of what "humanity" means, rather than in terms of "dehumanization". The Anthropology of the body and classic ethnographic studies help demystify trans-humanism beliefs about death, which are apparently attributed exclusively to technocratic societies but in fact have been shared by all cultures, thereby permitting to overcome a purely materialistic view. 


\section{References:}

Aibar, E., Díaz, J.A. (1994). Dos décadas de Evaluación de Tecnologías: del enfoque tecnocrático al diseño social. [Two decades of Technology Evaluation: From the technocratic approach to social design]. SISTEMA. num. 123 (November) pp. 95-113.

Aibar, E. (1996) La vida social de las máquinas: Orígenes, desarrollo y perspectivas actuales en la sociología de la tecnología. [Social life of the machines. Origins, development and perspectives in the sociology of technology]. Revista Española de Investigaciones Sociológicas (Journal of Sociological Research), 76, 141-170.

Aibar, E. (2006). Ciència, Tecnologia i Societat. [Science, Technology and Society]. Barcelona: UOC (Open University of Catalonia).

Aguilar, T. (2008). Ontologia Cyborg. El cuerpo en la nueva sociedad tecnológica. [Cyborg Ontology. The body in the new technological society] Barcelona: Gedisa.

BDigital Global Congress. (2011). URL: http://www.bdigitalglobalcongress.com/lang-In/2011/the-bdigital-global-congress/ , last access 26 July 2011.

Berger, $\mathrm{P}$ and Luckmann, T. (1966). La construcción social de la realidad. [Social Construction of Reality]. Buenos Aires: Amorrortu.

Campàs, J. (2005). El paper d'Internet en la cultura emergent del món actual (1945 - 2003). [Internet's role in the emerging culture of today's world (1945-2003)]

Doctoral Thesis. Dept. of Contemporary History. University of Barcelona.

o Dona Haraway: A cyborg manifesto”, pp. 96-97

o Human - machine interaction, pp. 270-274

o The digital body, pp. 439-446

o The identity, pp. 474-498

Clynes, M. E.,\& Kline, N. S. (1960). Cyborgs and space. Cyborg Handbook. New York: Routledge, 29-34.

Cole, M. (1995). Culture and cognitive Development: From Cross-cultural Research to Creating Systems of Cultural Mediation. Culture\&Psychology 1 (1), 2554. New Delhi: Sage.

David, P. A. (1985). Clio and the Economics of QWERTY. The American Economic Review, 75 (2), 332-337.

Douglas, M. (1970). Símbolos Naturales: Exploraciones en Cosmología. [Natural Symbols: Explorations in Cosmology]. Madrid: Alianza.

Downey, G.L., Dumit, J., and Williams, S. (1995). Cyborg Anthropology. Anthropologies of the Body, 10 (2), 264-269. 
Edwards, D., Potters, J. (1992). Discursive psychology. London: Sage.

Ellul, J. (1954). La edad de la técnica. [The Age of Tecnique]. Barcelona: Octaedro.

Esquirol, J. M. (2006). El Respeto o la Mirada Atenta. [The Respect or the Attentive Gaze]. Barcelona: Gedisa.

Evers, K. (2009). Neuroética. [Neuroethics]. Buenos Aires: Katz Editores.

Foucault, M. (1975). Vigilar y castigar. [Discipline and Punish]. Argentina: Siglo XXI.

Garay, A., Iñiguez, L., Martínez, L.M. (2005). La perspectiva discursiva en Psicologia Social [Discursive Perspective in Social Psychology]. UCES (University of Economics and Social Sciences), pp. 105-130.

Gergen, K. (1992). El yo saturado. [The Saturated Self]. Barcelona: Paidós.

Gray, C.H. (2002). Cyborg Citizen. Politics in the Posthuman Age. New York: Routledge.

Goffman, E. (1959). La presentación de la persona en la vida cotidiana. [The presentation of oneself in everyday life]. Madrid: Amorrortu.

Habermas, J. (2001). El futuro de la naturaleza humana. [The Future of Human Nature]. Barcelona: Paidós.

Haraway, D. (1991). A Cyborg Manifesto: Science, Technology, and SocialistFeminism in the Late Twentieth Century. In Simians, Cyborgs and Women: The Reinvention of Nature. New York: Routledge, pp. 149-181 URL:

http://www.stanford.edu/dept/HPS/Haraway/CyborgManifesto.html , last access 14 July 2011.

Heidegger, M. (1984). Ciencia y Técnica. [Science and Technology]. Chile: Editorial Universitaria.

Héritier, F. (1996). Masculino / Femenino. El pensamiento de la diferencia. [Male/female. The thought of difference]. Ariel.

Hughes, T. P. (1987). The evolution of large technological systems. In Bijker, W. E., Hughes, T. P., and Pinch, T. J., editors, The Social Construction of Technological Systems: New Directions in the Sociology and History of Technology, number 405, pp. 51-82. MIT Press.

Ihde, D. (2004). Los cuerpos en la tecnología. [Bodies in technology]. Barcelona: Editorial UOC, 2004.

Ishiguro, H. (2011). Intelligent Robotics Laboratory at Osaka University. URL: http://www.is.sys.es.osaka-u.ac.jp/index.In.html , last access 27 September 2011. 
Jonas, H. (1979). El principio de responsabilidad: Ensayo de una ética para la civilización tecnológica. [The imperative of responsability: In search of ethics for the technological age]. Barcelona: Herder, 1995.

Kaku, M. (2010). Theoretical Physics at the University of New York. URL: http://www.mkaku.org , last access 22 July 2011

Kurzweil, R. (2011a). URL: www.kurzweilai.net / Singularity Institute http://singinst.org/overview/whatisthesingularity/ , last access 8 September 2011.

Kurzweil, R. (2011b). URL: http://www.redesparalaciencia.com/80/redes/redes-10el-futuro-la-fusion-del-alma-y-la-tecnologia , last access 14 October 2011.

Kurzweil, R. (1999). The Age of Spiritual Machines. New York: Penguin Books.

Latour, B. (1999). La Esperanza de Pandora. Ensayos sobre la realidad de los estudios de la ciencia. [Pandora's Hope. Essays on the Reality of Science Studies]. Barcelona: Gedisa.

Latour, B. (1992). Ciencia en Acción. [Science in Action]. Barcelona: Labor.

Law, J. (1991). Introduction: monsters, machines and sociotechnical relations. In J. Law (Ed.): A sociology of monsters. Essays on Power, Technology and Domination. London: Routledge.

Le Breton, D. (1994) Lo imaginario del cuerpo en la tecnociencia. [The Imaginary of the Body in Technoscience]. In REIS (Spanish Journal of Sociological Research), 68, pp. 197-210.

Le Breton, D. (1990). Antropología del cuerpo y modernidad. [Anthropology of the Body and Modernity]. Buenos Aires: Nueva Visión.

Leeb, R. (2009). Institute for Knowledge Discovery at Technical University of Graz (Austria). URL:

http://ec.europa.eu/information society/activities/einclusion/docs/bci 02082006/gra z bci muller-putz.Pdf , last access 3 October 2011.

Lévi-Strauss, C. (1955). Tristes trópicos. [The Sad Tropics]. Barcelona: Paidós.

Lombard, M., Ditton, T. (1997). At the heart of it all: The concept of presence. Journal of Computer-Mediated Communication, 3 (2). URL:

http://jcmc.indiana.edu/vol3/issue2/lombard.html , last access 10 January 2012.

Llobera, J.R. (1999). Manual d'Antropologia Social. [Manual of Social Anthropology]. Barcelona: UOC (Open University of Catalonia).

Martí, J. (2008). La Cultura del Cos. [The culture of the body]. Barcelona: UOC (Open University of Catalonia). 
Morin, E. (1995). Sociología. [Sociology]. Madrid: Tecnos.

Ortega y Gasset, J. (1939). Meditación de la técnica y otros ensayos. [Meditation on technics and other essays]. Madrid: Alianza.

Pistorius, O. (2011). URL: http://en.wikipedia.org/wiki/oscar pistorius , last access 21 September 2011.

Pritchard, E.E. (1940). Los Nuer. [The Nuer]. Barcelona: Anagrama.

Rodríguez, R. (2006). Heidegger y la crisis de la época moderna. [Heidegger and the crisis of modern times]. Madrid: Síntesis.

Rogers, E. M. (1962). Diffusion of innovations. Free Press of Glencoe.

Seguí, J. (2005). Recension of Latour, B. (1999/2001), Pandora’s Hope. Essays on the Reality of Science Studies. Barcelona: Gedisa. URL:

http://www.construccionismosocial.info

http://www.jsegui.e.telefonica.net/Textos/Latour.pdf , last access 3 September 2011.

Sloterdijk, P. (1999). Normas para el parquet humano. [Rules for the human park]. Madrid: Siruela.

Stock, G. (2011). URL: http://www.gregorystock.net / http://www.youtube.com/watch?v= 0e88BldKZM\&feature=player embedded , last access 27 September 2011.

Spears, R., Lea, M., Postmes, T. (2002). Computer-Mediated Communication as a channel for social resistance. The Strategic Side of SIDE. Small Group Research, 33 (5): pp. 555-574.

The Guardian (2009). URL: http://www.guardian.co.uk/uk/2011/aug/09/uk-riotsmobile-phone-operators?INTCMP=SRCH , last access 10 August 2011.

Turkle, S. (2007). Authenticity in the age of digital companions. Interaction Studies, 8 (3), pp. 501-517.

Vayreda, A., Vila, I. and others (2009). Psicologia. [Psychology]. Barcelona: UOC (Open University of Catalonia)

Warwick, K. (2011). URL: http://www.kevinwarwick.com , last access 20 June 2011.

Wooller, J. (2010). URL: http://www.zdnet.com.au/perth-man-opts-for-microchipImplant-339304154.htm?tag=mantle skin;Happy , last access 14 October 2011.

World Transhumanism Association (2011) URL:

http://transhumanism.org/index.php/WTA/hvcs , last access 25 September 2011. 


\section{Key Terms:}

Agency: Given the possibility of natural hybridization between humans and machines (with a blur boundary), it is not clear who is performing the actions in order to improve their efficiency. Latour (1999) proposes to study the construction of this strong interaction/integration.

Transhumanism: The concept of lineal historical evolution after the post-humanist period, with the underlying belief that technology can transcend physical limitations of body. The World Transhumanism Association

(www.transhumanism.org/index.php/WTA/hvcs ) represents this paradigm.

Cyborg: Commonly understood as human-machine physical integration.

Cyborg Anthropology: An academic endeavor promoted by Downey, Dumit and Williams (1995)that suggests a different formulation of the history and subjectivities involved in the interaction/integration of humans and machines, not as a simple expression of cultures, but bearing in mind a possible reformulation of the traditional concept of Anthropos.

Dehumanization: A negative idea of the influence of technology on society. It has potential to transform the interpretation of reality leading to new unpredictable social challenges. It comes in part from the negative consequences of Second War World and the thought of some philosophers of Technique. In our article we claim it is more adequate to think of a mutation of the concept of humanization.

Explainability: One of the most important concepts of the Ethnomethodology of Discourse. It relates the objectification of social knowledge needed to develop daily habits with how individuals justify their actions socially when interacting with technology. This affects directly on the construction of psychosocial identity. 
Hybridization: In Biology, it refers to the process of mating organisms of different varieties or species to create a hybrid. Following the thesis of Cyborg Anthropology and the concept of psychosocial integration, there exists a natural hybridization between technological objects and humans.

Multi-Stability: The concept proposed by Ihde (2004) refers to the unpredictable uses of technology different from the originally intended ones. This is one of the difficulties to foresee technological consequences, and it undermines the long-term extrapolation of concrete case studies.

Psychosocial internalization: The way technological uses are integrated in the dialogical relation between individuals and society, which permits viewing the cyborg as a continuous whole in all that pertains to the study of man.

\section{Footnotes:}


${ }^{\text {i }}$ In the history of Psychology, B. F. Skinner was one of the first to propose that all behavior is controlled from outside, independently of any internal process. Obviously, his prospects have been revised leading to modern views on which we will centre our interest, such as Cultural Psychology or Psychology of Discourse, more in agreement with the idea that outer/inner symbiosis defines identity, and idea also proposed by Habermas.

ii We refer here to the concept of "human activities" in the sense of Cultural Psychology and the theses of L.S. Vigotsky (construction of the semiotic and symbolic reality) related to the refinements of Alexis N. Leontiev about human activity and the division of tasks in a social context.

iii At this point we notice the relevancy of the analysis of the discourse (Ethnomethodology) from the practical nature of language understood in the terms of the second Wittgenstein.

iv The theory of Jean Piaget (1981) relates, basically, the immaterial structures (thought) with the material structures (life) with the aim to accomplish with an adaptative function to the surroundings of the individual. According to this theory, "the origin of knowledge [...] does not lie in the objects, neither in the individual, but in the interactions - at first inextricable - between the subject and the objects.” This becomes a different perspective from the traditional Cartesian one, res cogitans versus res extensa.

v Vayreda mentions the work of K. Gergen (1992) “The saturated self” and follows the reasoning of S. Turkle to explain the mutation of the concept of identity as an adaptive process to the change that characterizes contemporary society.

vi The SIDE model is the opposite to that seeing "Internet as a context without social signals", which corresponds to the approach called "reduced social cues" - followed by authors like Siegel and McGuire or McGrath and Hollingshead - that emphasizes the negative effects of Internet (Vayreda, 2009).

${ }^{\text {vii }}$ Potter and Wetherell take as reference, among others, the reflection of the Second Wittgenstein on the practical nature of language as a performative act.

viii Berger and Luckmann (1966) remind us that, even in possible marginal situations, the actions of the individuals continue being inserted in the symbolic universe where they belong to. However, the construction of the discourse is an issue widely studied by Linguistic Ethnomethodology and the concept of explicability. 
ix Vayreda follows the thesis of Harré (1995) and of Discursive Psychology, as named by Edwards and Potter (1992), which study the psychological processes by which people exchange information that give meaning to their activities - including material tools - through discourse.

${ }^{x}$ Technological integration in the organism with the aim of palliating the effects of an illness drives us to the initial prospects of Cognitive Psychology and the parallelisms established in the past between the operation of the brain and that of a machine (computational analogy). This prospect consolidated the outer/inner dichotomy that current Psychology seems to refuse. Our approach is contextualized in the "discursive perspective".

${ }^{\mathrm{xi}}$ However, there remains the paradox that, given that a symbolic universe is the expression of order of all that belongs to it both human and non-human - and it is subjected, therefore, to mutation and constant maintenance along time (Esquirol, 2006), What kind of maintenance does transhumanism propose for the technological devices on which it relies?

xii The question we ask is whether the requirements to compete entail an explicit commitment not to incorporate future technological improvements for Pistorius's prostheses. Or, on the contrary, to what extent the rest of athletes will be allowed in the future to incorporate prostheses to their bodies in order to improve their performances.

\section{xiii http://www.reading.ac.uk/about/newsandevents/releases/pr16530.aspx Warwick’s research does not} seem to follow the computational analogy of Cognitive Psychology in its initial times. On the contrary, it adheres to the study of the operation of groups of neurons, in agreement with Fodor's modularity concept.

${ }^{\text {xiv }}$ Ellul $(1954,2003)$ establishes different categories of technique, among which "Human techniques” should be highlighted.

\footnotetext{
${ }^{\mathrm{xv}}$ Latour clearly distinguishes between 'technical' and 'technique', advising to use the former when a human has to resolve a difficulty or surmount an obstacle, which then becomes a 'technical problem'. Instead, 'technique' is a substantive that refers to a technological solution.
}

${ }^{x v i}$ The experiment of children interacting with the computer program Eliza, described by Turkle, can surely contribute valuable information on the attitude with which humans learn to ask for their own essence. 
${ }^{x v i i}$ It is well known the controversy generated by Jean Bricmont and Alan Sokal with their article "Transgressing the Boundaries: Towards to Transformative Hermeneutics of Quantum Gravity” published in the Social Text magazine (Sokal and Bricmont, 1996)

\section{http://www.physics.nyu.edu/faculty/sokal/transgress v2/transgress v2 singlefile.html. Despite} having been written with apparent rigor, the article was the product of invention. The aim of the two scientists was to show that a theory of scientific knowledge built on apparently coherent terms could be taken seriously in the sociological context. The error of the journal provided ground for the authors' very strong criticism to the postmodern sociological perspective on scientific knowledge, and led to a series of responses from both sides.

xviii The model SCOT (Social Construction of Technology) is based on an interpretative flexibility of the controversies of the Relevant Social Groups and their closure mechanisms. The Systems approach contains a prospect based on interaction networks of interests and relations of diverse nature, but distinguishes between the technical content of a system and its social context (Aibar, 1996, 2006).

${ }^{\text {xix }}$ Latour and Ihde seem to agree on the capacity of technology (not neutral) to change the attribution of agency of the human as a result of hybridization. But they disagree that intentionality be the trait that distinguishes a human from a non-human.

${ }^{x x}$ E: Environmental / P: Psychological / I: Institutional and Political / S: Social / T: Technological / L: Legal / E: Economic.

${ }^{\text {xxi }}$ In this article we have respected the distinction between the concepts of Evaluation of Technologies and Impact Studies. The former is a more modern concept endowed of a global and symmetrical view in the study of the effects of devices. The latter was used previously to justify deterministic views on certain devices that attributed them the unilateral capacity to cause social, political and economic changes of wide cultural scope. According to Eduard Aibar, however, now the two concepts can be used indistinctly regardless of the standpoint and, therefore, it is necessary to pay attention to the content rather than the use of the terms.

${ }^{\text {xxii }}$ In this sense, Aibar and Díaz (1994) mention the precepts of what has been called Social Evaluation of Technology, namely: 1/ Distribution of information of interest on the controversies, 2/ Increase of the number of relevant factors and, 3/ Greater involvement of Relevant Social Groups (RSG).

xxiii In his analysis, the economist Paul David (1985) explores the reasons why the configuration of the keyboards of early typewriters (QWERTY) succeeded, despite the existence of technologically more advanced arrangements that would increase the performance of their users. However, even today, computers still incorporate the QWERTY configuration. 
